\title{
Effects of Temperature and Frequency on Dielectric Properties of $\mathrm{LiCo}_{3 / 5} \mathrm{Fe}_{1 / 5} \mathrm{Cu}_{1 / 5} \mathrm{VO}_{4}$
}

\author{
Moti Ram \\ Department of Physics and Meteorology, Indian Institute of Technology, Kharagpur, West Bengal-721302, India
}

\begin{abstract}
In the present work, an evaluation of the relaxation behavior of a system (LiCo $\left.{ }_{3 / 5} \mathrm{Fe}_{1 / 5} \mathrm{Cu}_{1 / 5} \mathrm{VO}_{4}\right)$ has been undertaken. This system was synthesized by solution-based chemical route. Dielectric measurements were made using complex impedance method. Frequency dependence of real part of dielectric constant $\left(\varepsilon_{r}^{\prime}\right)$ at different temperatures indicates the features of dielectric materials. Temperature dependence of $\varepsilon_{r}$ at different frequencies shows the dielectric anomalies in $\varepsilon_{r}{ }^{\prime}$ at different temperatures. Frequency dependence of tangent loss at different temperatures exhibits dielectric relaxation process in the material. The scaling behavior of tangent loss signifies the similar mechanism for relaxation process at various temperatures.
\end{abstract}

Keywords: Powders: chemical preparation; Tangent loss, Dielectric constant, Dielectric Relaxation, Dielectric anomalies.

\section{Introduction}

An increasing interest has developed in recent years to study the lithiated transition metal oxides, which can be used for different technological applications [1-3]. The properties of such compounds can be modified by substituting them with different transition metal ions. The dielectric behavior of these compounds has evoked the interest of researchers in recent past and some results have been reported [4-8]. This was motivated to prepare a $\mathrm{LiCo}_{3 / 5} \mathrm{Fe}_{1 / 5} \mathrm{Cu}_{1 / 5} \mathrm{VO}_{4}$ compound and study its dielectric properties. The $\mathrm{LiCo}_{3 / 5} \mathrm{Fe}_{1 / 5} \mathrm{Cu}_{1 / 5} \mathrm{VO}_{4}$ is interesting due to it's good transport behavior and mechanically strangeness. Furthermore, this compound has importance in the fundamental understanding of the physical processes as well as its applications for technological purposes. The complex dielectric constant $\left(\varepsilon^{*}\right)$ of a system is related with impedance data by the equation $\left(\varepsilon^{*}=1 / j \omega C_{0} Z^{*}\right)$, where $Z^{*}$ is the complex impedance, $C_{0}=\varepsilon_{0} A / t$, $t$ is the thickness of the sample, $A$ is the effective area of the electrodes, $\varepsilon_{\mathrm{o}}$ is the permittivity of free space $\left(8.854 \times 10^{-12}\right.$ $\mathrm{F} / \mathrm{m}), \mathrm{j}=(-1)^{1 / 2}$ and $\omega=2 \pi \mathrm{f}$ is the angular frequency. The complex impedance spectroscopy methods have been used successfully for the study of dielectric properties of these materials, which resolves the contributions and relative importance to electrical conduction and/or polarization of different phenomena in the studied frequency region [9-11]. The present study has been undertaken to investigate the dielectric studies as a function of temperature and frequency of a $\mathrm{LiCo}_{3 / 5} \mathrm{Fe}_{1 / 5} \mathrm{Cu}_{1 / 5} \mathrm{VO}_{4}$ system, which has cubic unit cell structure with lattice parameters $a=8.2756$ (3) $\AA$, and polycrystalline texture with grains of different sizes $\sim 0.2-3.0$ $\mu \mathrm{m}$ [12]. Dielectric properties of this compound have been studied by complex impedance spectroscopy method.

\section{Experimental Procedures}

Solution-based chemical route was used for the formation of $\mathrm{LiCo}_{3 / 5} \mathrm{Fe}_{1 / 5} \mathrm{Cu}_{1 / 5} \mathrm{VO}_{4}$ fine powder. The stoichiometric amounts of highly pure $\mathrm{LiNO}_{3}, \mathrm{Co}\left(\mathrm{NO}_{3}\right)_{2} \cdot 6 \mathrm{H}_{2} \mathrm{O}$, $\mathrm{Cu}\left(\mathrm{NO}_{3}\right)_{2} \cdot 3 \mathrm{H}_{2} \mathrm{O}, \mathrm{FeCO}_{3}$ and $\mathrm{NH}_{4} \mathrm{VO}_{3}$ were dissolved in distilled water and mixed together. $\mathrm{FeCO}_{3}$ was dissolved in warm distilled water in the presence of oxalic acid. After some time triethanolamine (TEA) was added maintaining a ratio of 3:1 with metal ions. $\mathrm{HNO}_{3}$ and oxalic acid were added to dissolve the precipitate and then the clear solution was evaporated at $\sim 200{ }^{\circ} \mathrm{C}$ temperature with continuous stirring. A fluffy, mesoporous and carbon-rich precursor mass was formed by complete evaporation of the solution. After grinding, the voluminous, fluffy and black carbonaceous mass was calcined at $550{ }^{\circ} \mathrm{C}$ for $3 \mathrm{~h}$ to produce the desired phase that is confirmed by X-ray diffraction analysis. The calcined powder was cold pressed into circular disc shaped pellets of diameter of 12-13 mm and various thicknesses with polyvinyl alcohol as the binder using hydraulic press at a pressure of $\sim 7.85-9.81 \mathrm{MPa}$. These pellets were then sintered at $575{ }^{\circ} \mathrm{C}$ for $2 \mathrm{~h}$ followed by slow cooling process. Subsequently, the pellets were polished by fine emery paper to make their faces smooth and parallel. The pellets were finally coated with conductive silver paint and dried at $150{ }^{\circ} \mathrm{C}$ for $3 \mathrm{~h}$ before carrying out electrical measurements. The electrical/dielectric measurements were carried out by applying a voltage of $\sim 0.701 \mathrm{~V}$ using a computer-controlled frequency response analyzer (HIOKI LCR Hi TESTER, Model: 3532-50) with varying temperature over the frequency range of $10^{2}-10^{6} \mathrm{~Hz}$.

\section{Results and Discussion}

Temperature dependence of $\varepsilon_{\mathrm{r}}^{\prime}$ at different frequencies is given in Fig. 1(a). It is seen from the figure that $\varepsilon_{\mathrm{r}}$ increases with rise in temperature and passes through a peak value $\left(\varepsilon_{\mathrm{r}}^{\prime}\right)_{\max . .}$ The peak temperature $\left(\mathrm{T}_{\text {max. }}\right)$ corresponds to $\left(\varepsilon_{\mathrm{r}}^{\prime}\right)_{\max }$ is shifting toward high temperature side upon increasing frequency. The broadening or diffuseness of dielectric peaks occurs mainly due to statistical composition fluctuations, which must occur if crystallographically equivalent sites are occupied randomly by different cations $[13,14]$. The value of $\mathrm{T}_{\text {max. }}=270,275,280$ and $290{ }^{\circ} \mathrm{C}$ with $\left(\varepsilon_{\mathrm{r}}^{\prime}\right)_{\max .} \sim 2546,2129$, 1583 and 857 are observed for $50,100,200$ and $500 \mathrm{kHz}$, respectively. 


\section{International Journal of Science and Research (IJSR) \\ ISSN (Online): 2319-7064}

Index Copernicus Value (2013): 6.14 | Impact Factor (2014): 5.611

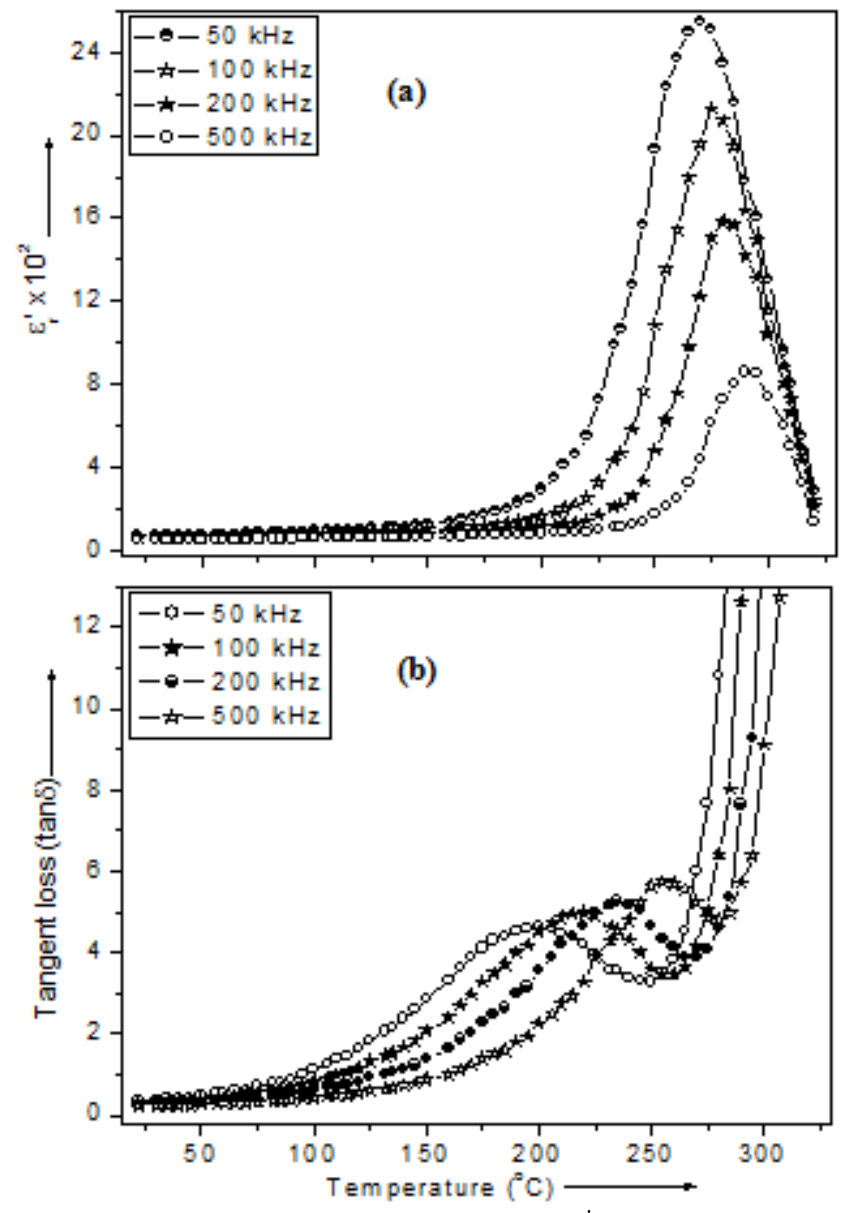

Figure 1: Temperature dependence of $\varepsilon_{\mathrm{r}}^{\prime}(\mathrm{a})$ and $\tan \delta$ (b) at different frequencies.

Temperature dependence of tangent loss $(\tan \delta)$ at different frequencies is presented in Fig. 1(b). The pattern of variation shows the $\tan \delta$ peak, which shifts toward high temperature side upon increasing the frequency. Also, the peak value of $\tan \delta$ increases with increase in frequency. These types of characteristics suggest the presence of dielectric relaxation process in the material $[15-17,9]$.

Fig. 2(a) shows the frequency dependence of $\varepsilon_{\mathrm{r}}^{\prime}$ at different temperatures. The value of $\varepsilon_{\mathrm{r}}^{\prime}$ decreases with increasing frequency, and then stabilized above $100 \mathrm{kHz}$. The high value of $\varepsilon_{\mathrm{r}}^{\prime}$ at low frequencies increases with decreasing frequency and increasing temperature may be due to electrode polarization arising usually from space-charge accumulation at the material-electrode interface [9, 12]. These are features of dielectric materials $[14,9]$.

Frequency dependence of $\tan \delta$ at different temperatures is given in Fig. 2(b). The tangent loss shows peak, which indicates the dielectric relaxation in the material. It is evident from Fig. 2(b) that the position of the peak shifts to higher frequencies with rise in temperature. This behavior is supposed to be due to the existence of broad spectrum of the relaxation times [10]. The frequency corresponding to peak is called relaxation frequency $\left(f_{\max }\right)$. It relates with relaxation time $\left(\tau_{\mathrm{d}}\right)$ as $\tau_{\mathrm{d}} \cdot 2 \pi \mathrm{f}_{\text {max. }}=1$. The variation of $\mathrm{f}_{\text {max. }}$ as a function of temperature is shown in Fig. 3. The value of $f_{\max }$ increases with rise in temperature and follows the Arrhenius relation $\left[f_{\max .}=f_{o} \exp \left(-E_{a} / k_{B} T\right)\right]$, where $f_{o}$ is the pre-exponential term, $\mathrm{k}_{\mathrm{B}}$ is the Boltzmann constant, $\mathrm{E}_{\mathrm{a}}$ is the activation energy, and $\mathrm{T}$ is the absolute temperature. The value of $\mathrm{E}_{\mathrm{a}}$ is estimated as $\sim\left(0.530 \pm 0.025 \mathrm{eV}\right.$ at $\left.50-250{ }^{\circ} \mathrm{C}\right)$ with the help of slope of Fig. 3 and Arrhenius relation.

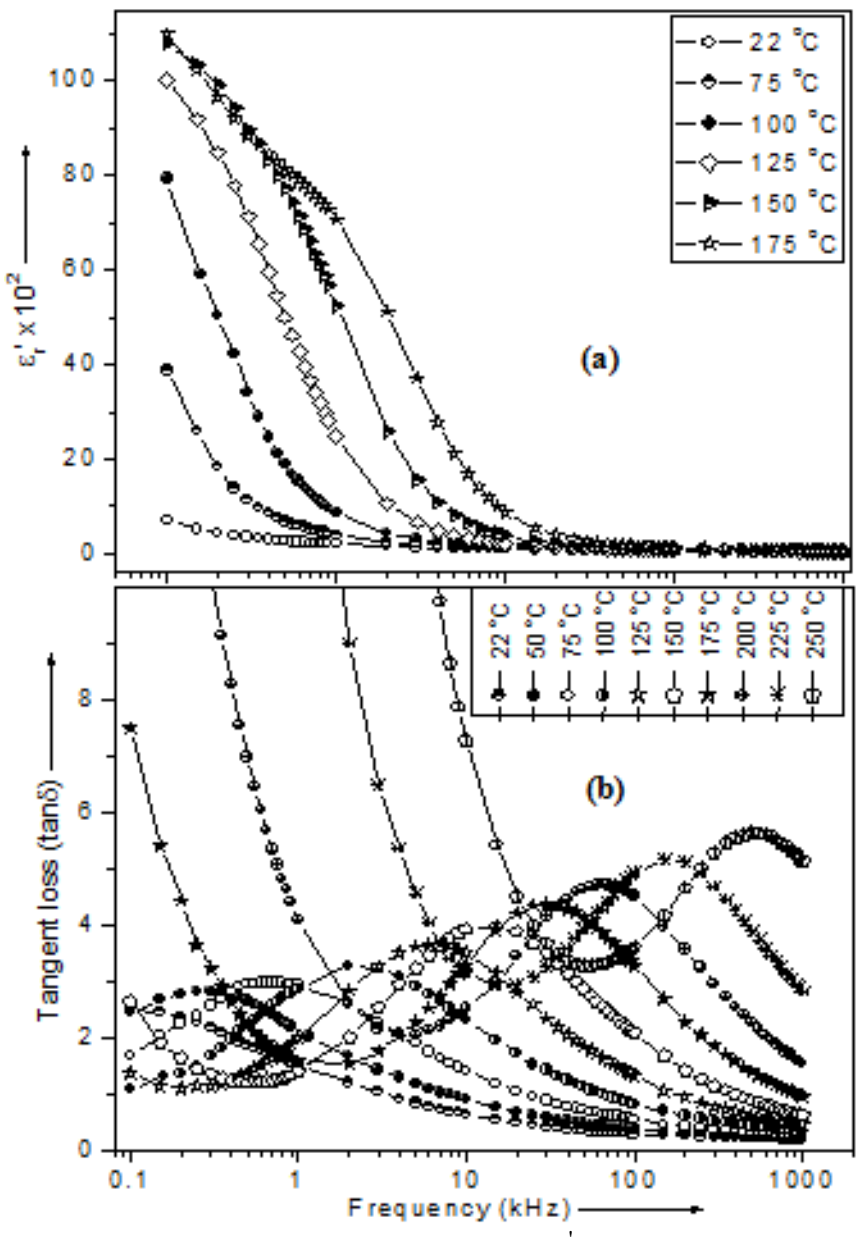

Figure 2: Frequency dependence of $\varepsilon_{\mathrm{r}}^{\prime}(\mathrm{a})$ and $\tan \delta(\mathrm{b})$ at different temperatures.

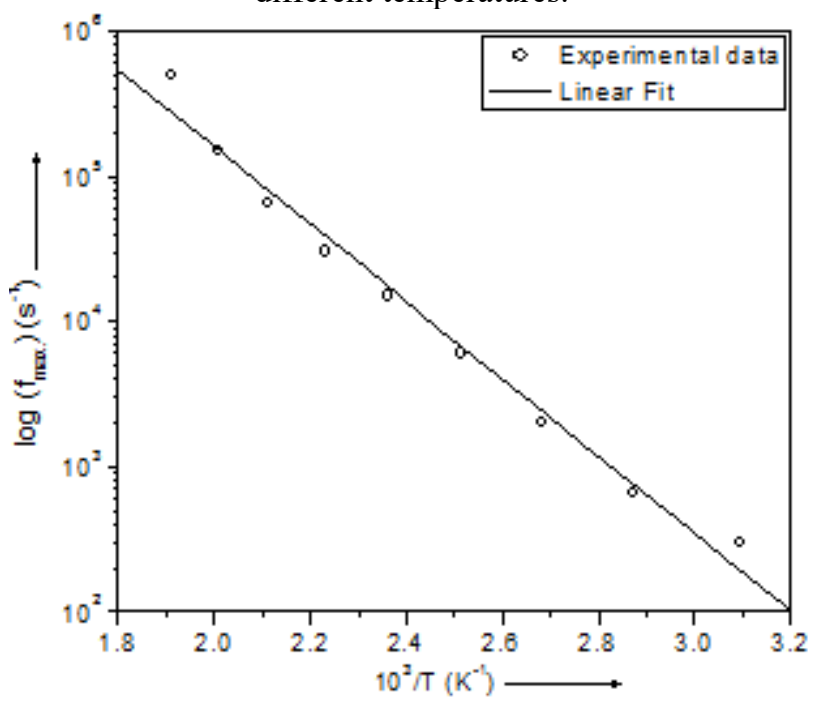

Figure 3: Variation of relaxation frequency $\left(f_{\max }\right)$ as a function of temperature.

Frequency dependence of a.c. conductivity $\left(\sigma_{\mathrm{ac}}\right)$ at different temperatures is presented in Fig. 4. It is observed from the figure that $\sigma_{\mathrm{ac}}$ decreases with decreasing frequency and becomes independent of frequency after a certain value. This value is known as hopping frequency and it corresponds to

\section{Volume 4 Issue 11, November 2015}




\section{International Journal of Science and Research (IJSR) \\ ISSN (Online): 2319-7064}

Index Copernicus Value (2013): 6.14 | Impact Factor (2014): 5.611

polaron hopping of charged species. Extrapolation of the part below the hopping frequency will

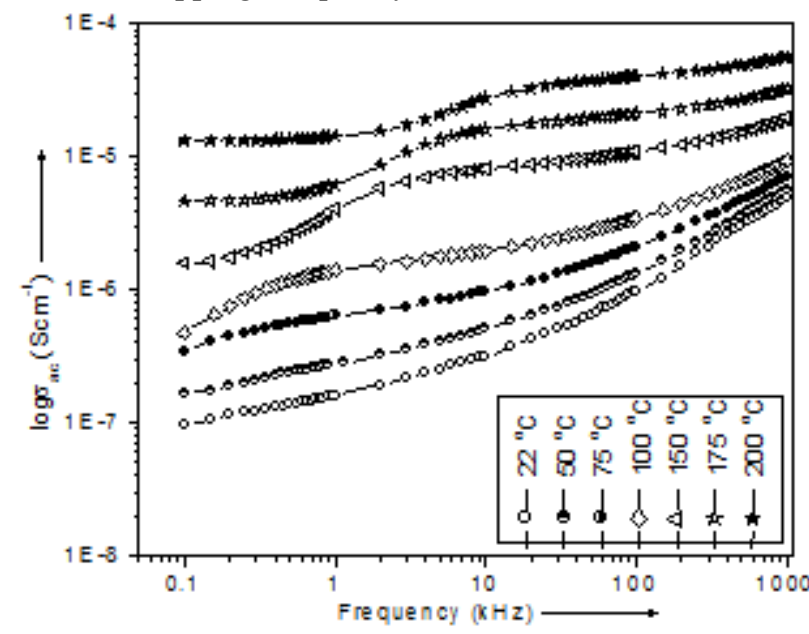

Figure 4: Frequency dependence of $\sigma_{\mathrm{ac}}$ at different temperatures.

give $\sigma_{\mathrm{dc}}$. The shift of hopping frequency toward high frequency side suggests that, a hopping type mechanism for electrical conduction in the material is present and it obeys the Jonscher's power equation $\left[\sigma(\omega)=\sigma_{\mathrm{dc}}+\mathrm{A}(\omega)^{\mathrm{n}}\right]$, where $\mathrm{n}$ is the frequency exponent in the range of $0 \leq \mathrm{n} \leq 1$ and $\mathrm{A}$ is a constant that depends upon temperature [18]. Furthermore, $\sigma_{\mathrm{ac}}$ in Fig. 4 decreases with decreasing frequency at very low frequencies and high temperatures, this drop correlating quit well with the increase in $\varepsilon_{\mathrm{r}}$ in Fig. 2(a).

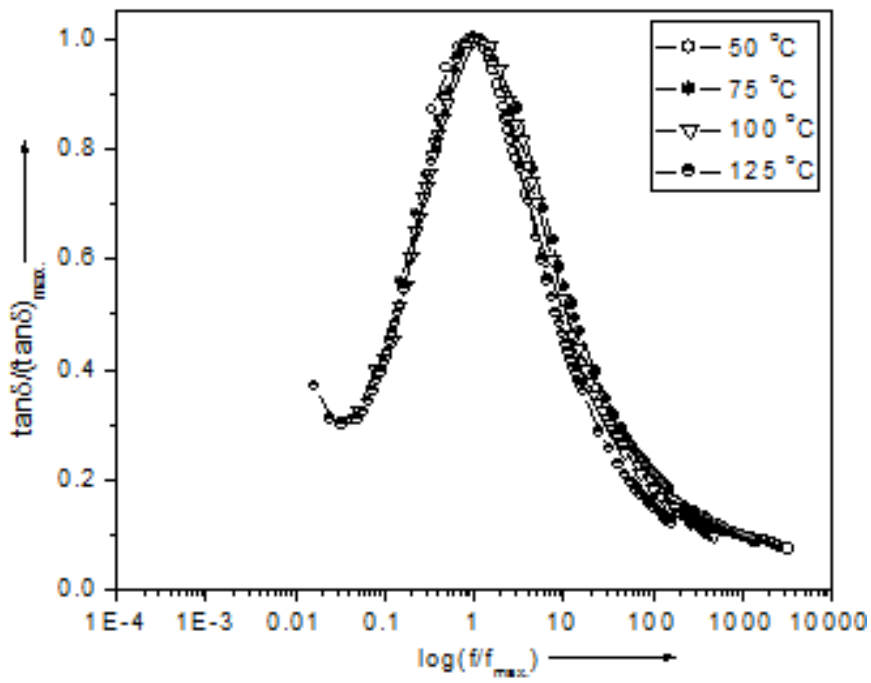

Figure 5: Variation of $(\tan \delta) /(\tan \delta)_{\max }$ with $\log \left(\mathrm{f} / \mathrm{f}_{\max }\right)$ at different temperatures.

Fig. 5 shows the variation of $(\tan \delta) /(\tan \delta)_{\max }$ with $\log \left(\mathrm{f} / \mathrm{f}_{\text {max. }}\right)$ (i.e., master curve) at different temperatures, where $f_{\max }$. corresponds to the frequency of loss peak in the $\tan \delta$ versus $\log \mathrm{f}$ plots. These master curves explain scaling behavior of the sample. It is seen from Fig. 5 that the entire dielectric loss data can be collapsed into one master curve. It suggests about temperature independence behavior of the master curve. This feature signifies the similar mechanism for relaxation process at various temperatures.

\section{Conclusions}

In summary, a $\mathrm{LiCo}_{3 / 5} \mathrm{Fe}_{1 / 5} \mathrm{Cu}_{1 / 5} \mathrm{VO}_{4}$ system was synthesized by solution-based chemical method. Temperature dependence of $\varepsilon_{\mathrm{r}}^{\prime}$ at different frequencies indicates dielectric anomalies in $\varepsilon_{\mathrm{r}}$ at different temperatures. The presence of dielectric relaxation phenomena in the material has been indicated by frequency dependence of $\tan \delta$ at different temperatures. The variation of relaxation frequency with temperature follows the Arrhenius relation. The scaling behavior of $\tan \delta$ suggests that the relaxation mechanism is temperature independent.

\section{Acknowledgements}

The author is grateful to the Nanomaterials Laboratory of the Department of Chemistry and Central Research Facility, Indian Institute of Technology, Kharagpur-721302 (W.B.), India, for providing facilities to conduct experiments.

\section{References}

[1] B. K. Kuanr, and G. P. Srivastava, "Dispersion observed in electrical properties of titanium- substituted lithium ferrites", Journal of Applied Physics, vol. 75, no. 10, pp. 6115-6117, 1994.

[2] C. Julien, M. Massot, and C. P. Vicente, "Structural and vibrational studies of $\mathrm{LiNi}_{1-\mathrm{y}} \mathrm{Co}_{\mathrm{y}} \mathrm{VO}_{4}(0 \leq \mathrm{y} \leq 1)$ ", Materials Science Engineering B, vol. 75, no. 1, pp. 612, 2000.

[3] G. T. K. Fey, and D. L. Huang, "Synthesis, characterization and cell performance of inverse spinel electrode materials for lithium secondary batteries", Electrochimca Acta, vol. 45, no. 1-2 , pp. 295-314, 1999.

[4] P. V. Reddy, and T. S. Rao, "Dielectric behaviour of mixed Li-Ni ferrites at low frequencies", Journal of Less Common Metals, vol. 86, pp. 255-261, 1982.

[5] M. A. Arillo, M. L. Lopez, E. Perez-Cappe, C. Pico, and M. L. Veiga, "Crystal structure and electrical properties of $\mathrm{LiFeTiO}_{4}$ spinel", Solid State Ionics, vol. 107, no. 3-4 , pp. 307-312, 1998.

[6] S. Selvasekarapandian, M. S. Bhuvaneswari, S. Fujihara, and S. Koji, "A comparative study of structural and impedance spectroscopic analysis of $\mathrm{Li}_{x} \mathrm{MVO}_{4} \quad(\mathrm{M}=\mathrm{Ni}, \quad \mathrm{Co} ; \quad x=0.8,1.0,1.2) "$, Acta Meterialia, vol 54, no. 7, pp.1767-1776, 2006.

[7] S. A. Mazen, F. Metawe, and S. F. Mansour, "IR absorption and dielectric properties of Li-Ti ferrite", Journal of Physics. D: Applied Physics, vol. 30, no.12, pp. 1799-1808, 1997.

[8] M. Ram, and S. Chakrabarti, "Dielectric and modulus behavior of $\mathrm{LiFe}_{1 / 2} \mathrm{Ni}_{1 / 2} \mathrm{VO}_{4}$ ceramics", Journal of Physics and Chemistry of Solids, vol. 69, no. 4, pp. 905-912, 2008.

[9] M. E. Lines, and A. M. Glass, "Principles and Application of Ferroelectrics", Oxford University Press, UK, 1977.

[10] A. K. Jonscher, "Dielectric Relaxation in Solids", Chelsea Dielectric Press, London, 1983. 
[11] J. R. MacDonald, "Impedance Spectroscopy: Emphasizing Solid Materials and Systems", John Wiley \& Sons, New York, 1987.

[12] M. Ram, "Transport mechanism in a ceramic system: $\mathrm{LiCo}_{3 / 5} \mathrm{Fe}_{1 / 5} \mathrm{Cu}_{1 / 5} \mathrm{VO}_{4}$ ", Journal of Alloys Compounds, vol. 509, no. 40, pp. 9659-9662, 2011.

[13] T. Kar, and R. N. P. Choudhary, "Structural, dielectric and electrical conducting properties of $\mathrm{CsB}^{\prime} \mathrm{B} " \mathrm{O} 6$ $\left(B^{\prime}=\mathrm{Nb}, \mathrm{Ta} ; \mathrm{B} "=\mathrm{W}, \mathrm{Mo}\right)$ ceramics", Materials Science Engineering B, vol. 90, no. 3, pp. 224-233, 2002.

[14] N. K. Singh, A. Panigrahi, and R. N. P. Choudhary, "Structural and dielectric properties of $\mathrm{Ba}_{5} \mathrm{EuTi}_{3 \text { - }}$ ${ }_{x} \mathrm{Zr}_{\mathrm{x}} \mathrm{Nb}_{7} \mathrm{O}_{30}$ relaxor ferroelectrics", Materials Letters, vol. 50, no.1, pp. 1-5, 2001.

[15] M. Adamczyk, A. Molak, and Z. Ujma, "The influence of axial pressure on relaxor properties of $\mathrm{BaBi}_{2} \mathrm{Nb}_{2} \mathrm{O}_{9}$ ceramics", Ceramics International, vol. 35, no. 6, pp. 2197-2202, 2009.

[16] K. Prabakar, S. K. Narayandass, and D. Mangalaraj, "Dielectric and electric modulus properties of vacuum evaporated $\mathrm{Cd}_{0.8} \mathrm{Zn}_{0.2} \mathrm{Te}$ thin films", Materials Science Engineering B, vol. 98, no. 3, pp. 225-231, 2003.

[17] K. S. Rao, P. M. Krishna, T. S. Latha, and D. M. Prasad, "Impedance-spectroscopy analysis and piezoelectric properties of $\mathrm{Pb}_{2} \mathrm{KNb}_{5} \mathrm{O}_{15}$ ceramics", Materials Science Engineering B, vol. 131, no. 1-3, pp. 127-134, 2006.

[18] A. K. Jonscher, "The 'universal' dielectric response", Nature, vol. 267, no. 5613, pp. 673-679, 1977. 